Vol. 1 No. 1, Feb 2021, hlm. 19 - 24

DOI: https://doi.org/10.33330/.v1i1.1014

Available online at http:// jurnal.stmikroyal.ac.id/index.php/jutsi

\title{
IMPLEMENTASI SISTEM APLIKASI E-COMMERCE TOKO BUSANA SERBA TIGA PULUH LIMA RIBU BERBASIS WEB
}

\author{
Nurainun Siregar ${ }^{1}$, Muh Saleh Malawat ${ }^{2}$, Andri Nata ${ }^{3^{*}}$ \\ ${ }^{1}$ Mahasiswa Prodi Manajemen Informatika, STMIK Royal \\ ${ }^{2}$ Prodi Manajemen, Universitas Asahan \\ ${ }^{3}$ Prodi Manajemen Informatika, STMIK Royal \\ e-mail : andrinata0202@gmail.com
}

\begin{abstract}
Internet connection is now a necessity to make it easier to access and develop information. Along with the wide reach of the internet, it is currently being pioneered by many companies that develop their sales business along with the development of sales information and online sales trends or called e-commerce in selling and selling here. Fifty-five thousand shops have participated in enlivening the online market, which provides sales. online that can be used without having to come to the store, to advance technological advances in digital and in the era of connectivity within a network.It is hoped that business people and consumers can make it easier for technology that is growing rapidly and rapidly so that they can easily shop with the support of a stable network and, what you want can be accessed quickly, and can help ecommerce businessmen easily. marketing the products they sell to be precise at this thirty-five thousand department store has also enlivened e-commerce.
\end{abstract}

Keywords : ImplemantionAndDesain E-Commerce Systems

\begin{abstract}
Abstrak : Koneksi internet saatinimenjadi kebutuhan untuk mempermudah mengaksesdan perkembangan informasi. Seiring dengan luasnya jangkauan internet saat ini dipepuleri oleh banyaknya perusahaan yang mengembangkan usahanya penjualan seiring berkembangnya informasi penjualan dan trend penjualan online atau disebut e-commerce dalam jual beli disini Toko serba tiga puluh lima ribu ikut serta meramaikan pasar online, yang dimana memberikan penjualan secara oline yang bias digunakan tanpa harus dating ke toko, untuk mengedepankan kemajuan teknologi diera digital dan di era konektipitas di dalam sebuah jaringan. Diharapkan para pelaku pembisnis dan para konsumen dapat dimudahkan adanya teknologi yang semangkin cepat berkembang pesat dan cepat sehingga dapat mudah berbelanja dengan dukungan jaringan yang setabil dan apa yang diakses dapat diakses dengan cepat dan dapat membantu para pembisnis e-commerce dengan mudah memasarkan produk-produk yang mereka jual tepatnya pada Toko Serba Tiga Puluh Lima Ribu Kisaran ini turut meramaikan e-commerce.
\end{abstract}

Kata Kunci : Implemantasi Dan PerancanganSistemAplikasi E-Commerce 
Vol. 1 No. 1, Feb 2021, hlm. 19 - 24

DOI: https://doi.org/10.33330/.v1i1.1014

Available online at http:// jurnal.stmikroyal.ac.id/index.php/jutsi

\section{PENDAHULUAN}

Online shope atau disebut E-commerce adalah sebuah penjualan berbasis web atau digital yang didukung koneksi jaringan internet, yang dimana seiring berkembang nya teknologi dan informasi dalam dunia digital dan berkembang nya juga sistem penjualan dari penjualan yang tradisional menajdi penjualan electronik atau disebut E-commerce yang dimana penjualan melalui media dan jaringan internet sehingga mengikuti trend dalam dunia usaha dan bisnis yang sedang berkembang, untuk meningkatnya penjualan dan omset yang mencakup lebih luas lagi pasaran, sehingga dapat mencakup banyak wilayah, tidak mencakup satu wilayah adanya koneksi jaringan internetlah semua dapat dimudahkan dengan menggunakan jaringan.

Pengguna E-commerce di indonesia sangatlah berkembang pesat banyaknya pelaku dan pembisnis atau pengusaha online yang ikut mengembangkan bisnisnya, untuk para konsumen transaksi pembelian yang diinginkan pilih E-commerce terpercaya, sehingga aman untuk bertransaksi agar tidak ada yang merasa dirugikan agar kita dapat berbelanja dengan mudah dan aman setiap produk yang kita inginkan. Perkembangan teknologi dan informasi saat sangat tumbuh sangat cepat disegala bidang maupun bisnis ataupun informasi digital sehingga dapat mudah digunakan untuk semua kalangan yang memiliki akses dan koneksi internet berkembangnya kegiatan ekonomi sekarang ini, diantaranya kegiatan bisnis E-commerce dalam aspek transaksi penjual dan pembelian tepatnya pada pelaku pembisnis pakaian.

Toko Busana Serba Tiga Puluh Lima Ribu Kisaran sebuah perusahan yang bergerak dibidang bisnis penjualan pakaian bermacam-macam jenis pakaian Kaos, baju anak-anak, dan daster, Toko Busana Serba Tiga Puluh Lima Ribu Kisaran berletak di Jln. Cokroaminoto, Kisaran, Kabupaten Asahan, Sumatera Utara Toko Busana Serba Tiga Puluh Lima Ribu Kisaran pada saat ini sistem pemasaran dalam penjualan pakaian masih melakukan transaksi manual sistem datang pilih bayar Toko Busana Serba Tiga Puluh Lima Ribu Kisaran tersebut, dimana jumlah pelanggan pada Toko Busana Serba Tiga Puluh Lima Ribu Kisaran terkadang mencapai simbol kurang lebih 50 pelanggan perbulannya, adapun jenis pakaian yang paling banyak diminati konsumen adalah pakaian baju kaos, blezer, batik, hal ini menjadi perioritas Toko Busana Serba Tiga Puluh Lima Ribu Kisaran tersebut ingin mengembangkan pemasaran dalam penjualan pakaian berbasis teknologi, untuk hal tersebut Toko Busana Serba Tiga Puluh Lima Ribu Kisaran harus berupaya meningkatkan kepuasan pelanggan dan menciptakan komunitas pelanggan, sehingga diperlukannya sistem penjualan berbasis onlin guna meningkatkan penjualan.

Dalam strategi bisnis yang menggunakan jasa koneksi interet menggunakan media digital dan teknologi informasi yang memberikan perusahaan suatu pandangan pada pelanggannya secara luas, dapat diandalkan sehingga semua prosessistemyang dapat dirancang dan digunakan dengan mudah oleh useratau pengguna. Berdasakan yang ada dilapangan maka penulis ingin membangun suatu sistem yang dapat membantu dalam pemasaran pakaian-pakaian tersebut, khususnya dalam segi pemesanan pakaian, layanan diskon pelanggan Toko Busana Serba Tiga Puluh Lima Ribu Kisaran dan laporan transaksi pemesanan dan juga dalam hal pembayaran dengan konsep Penjualan online dalam bentuk 
Vol. 1 No. 1, Feb 2021, hlm. 19 - 24

DOI: https://doi.org/10.33330/.v1i1.1014

Available online at http:// jurnal.stmikroyal.ac.id/index.php/jutsi

web yang user interface. Sistem ini diharapkan nantinya dapat mempublikasikan jasanya secara efektif dan efesien, dan jangkauan yang luas kepada masyarakat.

\section{METODE}

Perancangan adalah spesifikasi umum dan terinci dari pemecahan masalah berbasis komputer yang telah dipilih selama tahap analisis [1].

Dalam mengkembangkanya sistem ada beberapa tahap yang dimana bagian terpenting, yang dimana rancangan yang dirancang dapat digunakan dan dipakai degan mudah oleh pengguna sehingga dapat berjalan dari saat masuk kehalaman, menjadi member sampai melakukan transaksi.

\section{Pengertian Sistem}

Sistem dapat diartikan sebagai suatu kumpulan atau himpunan dari unsur, komponen, atau variabel yang terorganisir, saling berinteraksi, saling bergantung satu sama lain, dan terpadu [2].

Sistem adalah suatu jaringan kerja dari prosedur yang saling berhubungan, berkumpul bersama-sama untuk melakukan suatu kegiatan atau untuk menyelesaikan suatu sasaran yang tertentu.

\section{Karakteristik Sistem}

Karakteristik adalah karakter yang memiliki sebuah konsep terhadap sistem yang memiliki beberapa bagian model umum seperti proses, input dan output sistem setelah sistem diproses dan diolah lalu diinput masukan data dan dikeluaran melalui output sehingga menjadi informasi yang ditampilkan oleh sistem menjadi sebuah informasi.

\section{HASIL DAN PEMBAHASAN}

\section{Context Diagram (CD)}

Context Diagram merupakan langkah awal yang dilakukan sebelum membuat data flow diagram [3].

\section{Data Flow Diagram (DFD)}

Data Flow Diagram (DFD) adalah suatu diagram yang menggunakan notasi-notasi untuk menggambarkan arus dari data sistem, yang penggunaannya sangat membantu untuk memahami sistem secara logika, terstruktur dan jelas [4].

\section{Tampilan Program}

Berikut ini adalah gambar tampilan program sistem informasi data distribusi koran pada CV. Terang Jaya yang telah dirancang. 
Vol. 1 No. 1, Feb 2021, hlm. 19 - 24

DOI: https://doi.org/10.33330/.v1i1.1014

Available online at http:// jurnal.stmikroyal.ac.id/index.php/jutsi

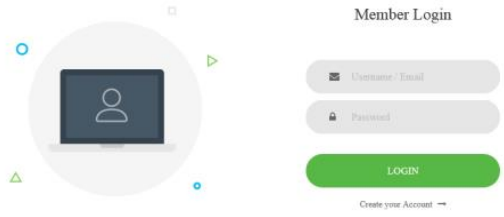

Gambar 1.TampilanForm Login Member

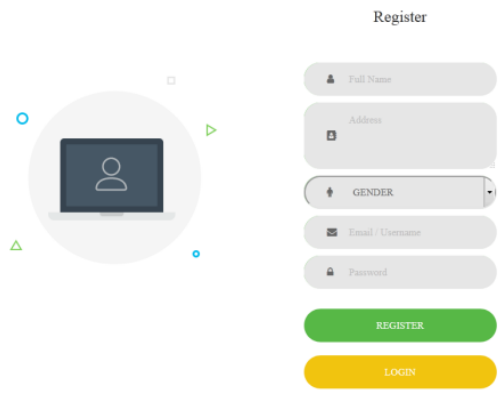

Gambar 2. Tampilan Register Member

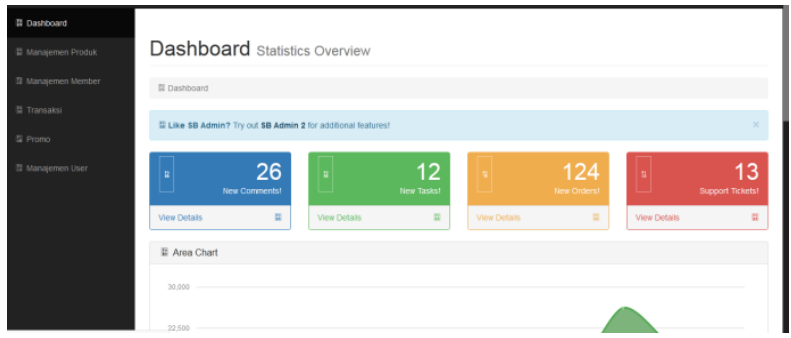

Gambar 3.Tampilan Dashboard Sistem admin
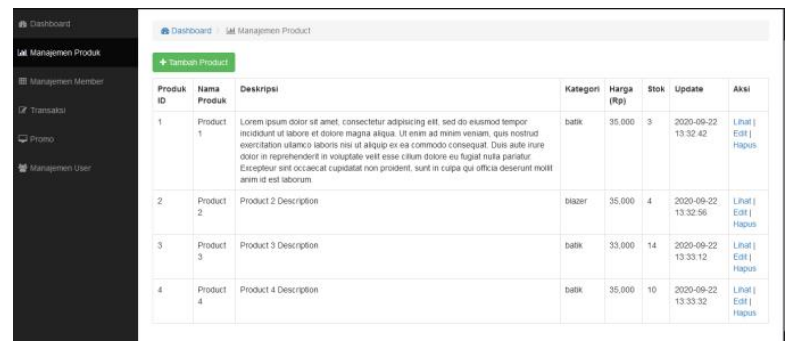

Gambar 4.Tampilan List Management Product 
Vol. 1 No. 1, Feb 2021, hlm. 19 - 24

DOI: https://doi.org/10.33330/.v1i1.1014

Available online at http:// jurnal.stmikroyal.ac.id/index.php/jutsi

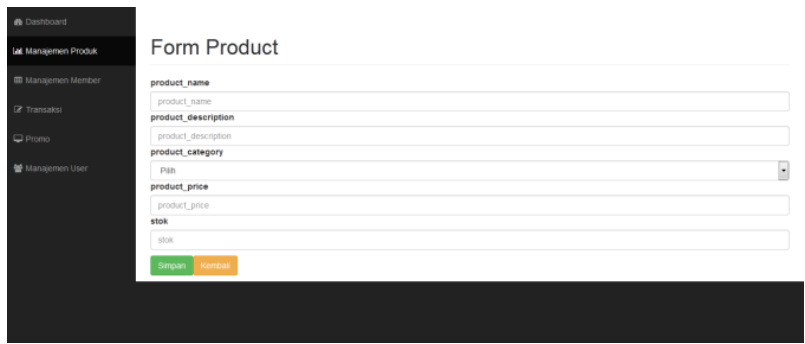

Gambar 5.Tampilan Input Product

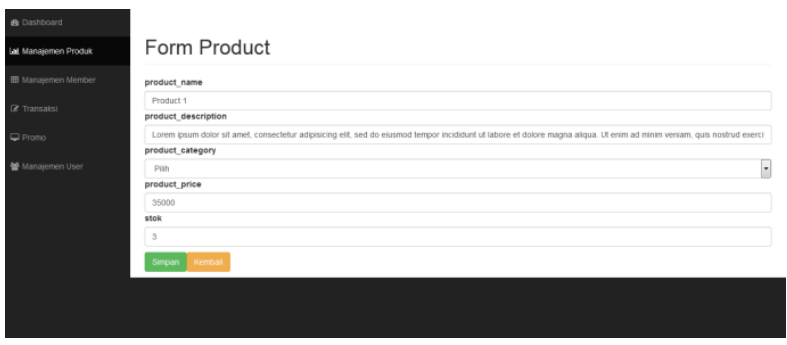

Gambar 6.Tampilan Edit Product

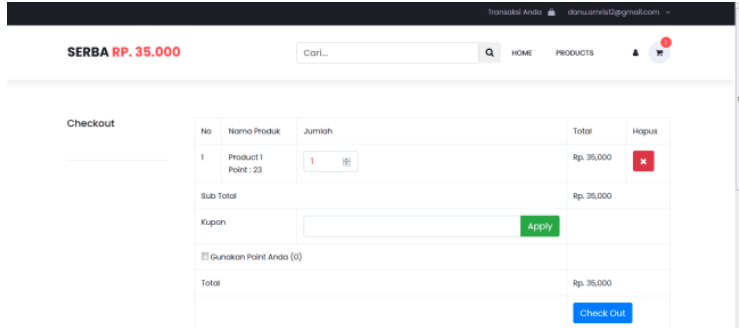

Gambar 7.Tampilan Manajemen Transactions

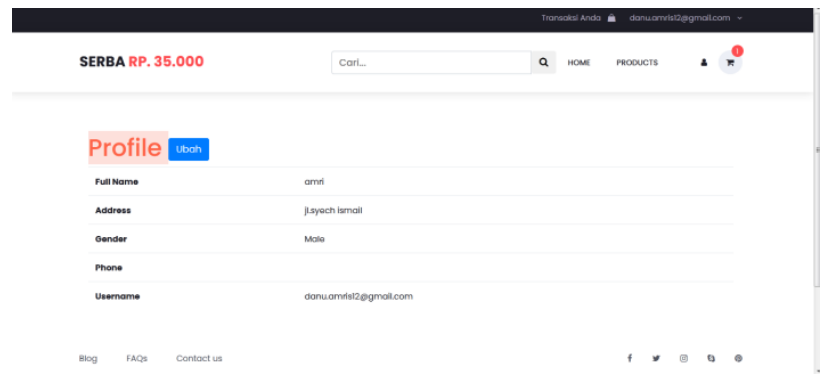

Gambar 8.Tampilan Form Profil Pengguna 
Vol. 1 No. 1, Feb 2021, hlm. 19 - 24

DOI: https://doi.org/10.33330/.v1i1.1014

Available online at http:// jurnal.stmikroyal.ac.id/index.php/jutsi

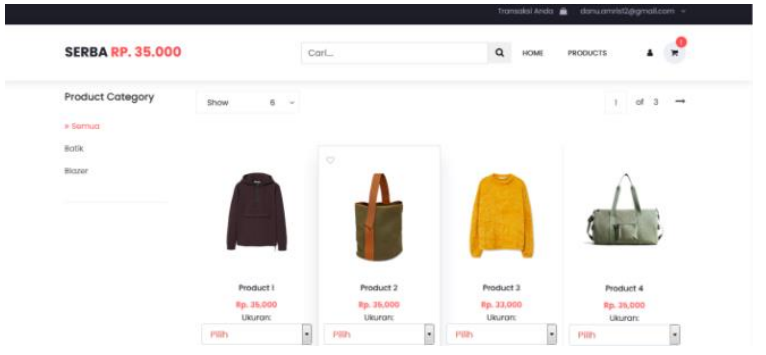

Gambar 9. Tampilan Beranda Toko

\section{SIMPULAN}

Dengan adanya sistem Online Berdagang menggunakan E-Commerce mempunyai banyak manfaat, diantaranya adalah dapat menekan biaya barang dan jasa, serta dapat meningkatkan kepuasan konsumen sepanjang yang menyangkut kecepatan untuk mendapatkan barang yang dibutuhkan dengan kualitas yang terbaik sesuai dengan harganya. Untuk mengembangkan dan menerapkan Sistem Online E-commerce diperlukan rangkaian proses yang memungkinkan dilakukannya analisis pelanggan sehingga perusahaan dapat mengenali pelanggan secara individual. Perusahaan harus tahu pelanggan mana yang berpotensi memberikan keuntungan besar dan mana yang merugikan. Ecomerce pada dasarnya adalah sebuah strategi pemasaran yang berkembang akibat perkembangan teknologi sehingga sifatnya adalah lebih besar peranannya dalam memelihara konsumen yang diartikan bahwa kemajuan teknologi dan jaringan.

\section{DAFTAR PUSTAKA}

[1] S. Akhmad and N. Hasan, "Perancangan Sistem Rawat Jalan Berasis web Pada Puskesmas Winog," Informatika, vol. 3, no. 1, pp. 28-34, 2015, [Online]. Available: https://ejournal.bsi.ac.id/ejurnal/index.php/Bianglala/article/view/574/465.

[2] D. Sukrianto, "Penerapan Teknologi Barcode pada Pengolahan Data Pembayaran Sumbangan Pembinaan Pendidikan (SPP)," Intra-Tech, vol. 1, no. 2, pp. 18-27, 2017.

[3] F. Ayu and W. Sholeha, "Rancang bangun sistem informasi penjadwalan mata pelajaran berbasis web pada smart center pekanbaru," Intra-Tech, vol. 3, no. 1, pp. 38-48, 2019.

[4] E. Iswandy, D. Sekolah, T. Manajemen, I. Komputer, and B. Balantai, "Jurnal TEKNOIF ISSN : 2338-2724 SISTEM PENUNJANG KEPUTUSAN UNTUK MENENTUKAN PENERIMAAN MAHASISWA DAN PELAJAR KURANG MAMPU Vol . 3 No . 2 Oktober 2015 Jurnal TEKNOIF ISSN : 2338-2724,” vol. 3, no. 2, 2015. 